\title{
Effect of Elastic Modulus of Adhesives on Stress Distribution in Weld-bonded Single Lap DP 600 Steel Joint
}

\author{
Min YOU ${ }^{1,2, a,{ }^{*}}$, Jian-Jun XU1, b Jian-Li LI ${ }^{2, c}$, and Hai-Zhou YU ${ }^{1, d}$ \\ 1 Hubei Key Laboratory of Hydroelectric machinery Design \& Maintenance, China Three \\ Gorges University, Yichang 443002, China \\ 2 Hubei Three Gorges Polytechnic, Yichang 443000, China \\ ayoumin@ctgu.edu.cn, b541949995@qq.com, ${ }^{\text {a }}$ lj@tgc.edu.cn, ${ }^{d}$ yu_haizhou@yahoo.cn \\ ${ }^{*}$ Corresponding author
}

Keywords: Weld-bonded joint, DP 600 steel, Elastic modulus of adhesives, Stress distribution, FEA

\begin{abstract}
The effect of the adhesives modulus from $0.05 \mathrm{GPa}$ to $6 \mathrm{GPa}$ on the stress distribution in weld-bonded single lap Dual Phase 600 steel joint was investigated using elastic finite element method (FEM). The results from the numerical simulation show that all the peak values of the stresses along the mid-bondline at the points near both ends of the over lap zone in the joint are increased significantly as the elastic modulus of adhesives increased. For the peak value of the stress $S x, S x y$ and Seqv along the adherend near the interface, it is not varied distinguish as the elastic modulus of adhesives is greater than $1.888 \mathrm{GPa}$. It is recommended that the suitable elastic modulus of adhesives be about 2 GPa for a weld-bonded single lap DP 600 steel joint.
\end{abstract}

\section{Introduction}

The development of the light weight structure in the aerospace, railroad passenger cars and automobile ind ustry was rapidly [1-3] including higher yield stress metal sheets of Dual Phase (DP) steel etc. Darwish and Al-Samhan [3] pointed that for rationale design of weld-bonded joints, adhesives with the less Young's modulus available should be coupled with maximum permissible gap thickness. The numerical studies were carried by authors to investigate the effect of the adhesive differed in the elastic modulus for the bondline [4] or the fillet [5] on the stress distribution in the weld-bonded aluminum single lap joints and the results showed that the stress distribution in the overlap zone was evidently affected by the elastic modulus of adhesives. In recent work, the effect of nugget size on the stress distribution of the weld-bonded single lap DP 600 Steel joint has been down [6]. The goal of this work is to study the effect of the elastic modulus of adhesives on the stress distribution in the weld-bonded single lap DP 600 steel joint.

\section{Finite Element Model and Mesh}

The model and mesh were built using the ANSYS finite element software as shown in Fig.1 and Fig.2a. There are two paths shown in Fig. $2 \mathrm{~b}$ and the one (path1) is along the mid-bondline and another (path2) along the adherend near the interface. The properties of the materials used in this study are listed in Table 1. The load applied was taken as $2 \mathrm{kN}$ and the dimensions of the DP 600 steel alloy adherend were made in accordance with the Chinese Standard GB 7124. The triangular element was used for both bondline and the nugget and the quadrilateral element for adherend (Fig.2). The thickness of the bondline was set as $0.2 \mathrm{~mm}$ and divided into 4 layers. To investigate the effect of the elastic modulus of adhesives thoroughly, four adhesives were taken into account with the modulus of $0.05 \mathrm{GPa}, 1.888 \mathrm{GPa}, 2.875 \mathrm{GPa}$ and $6 \mathrm{GPa}$ respectively. 
Table 1 Mechanical Properties of Materials

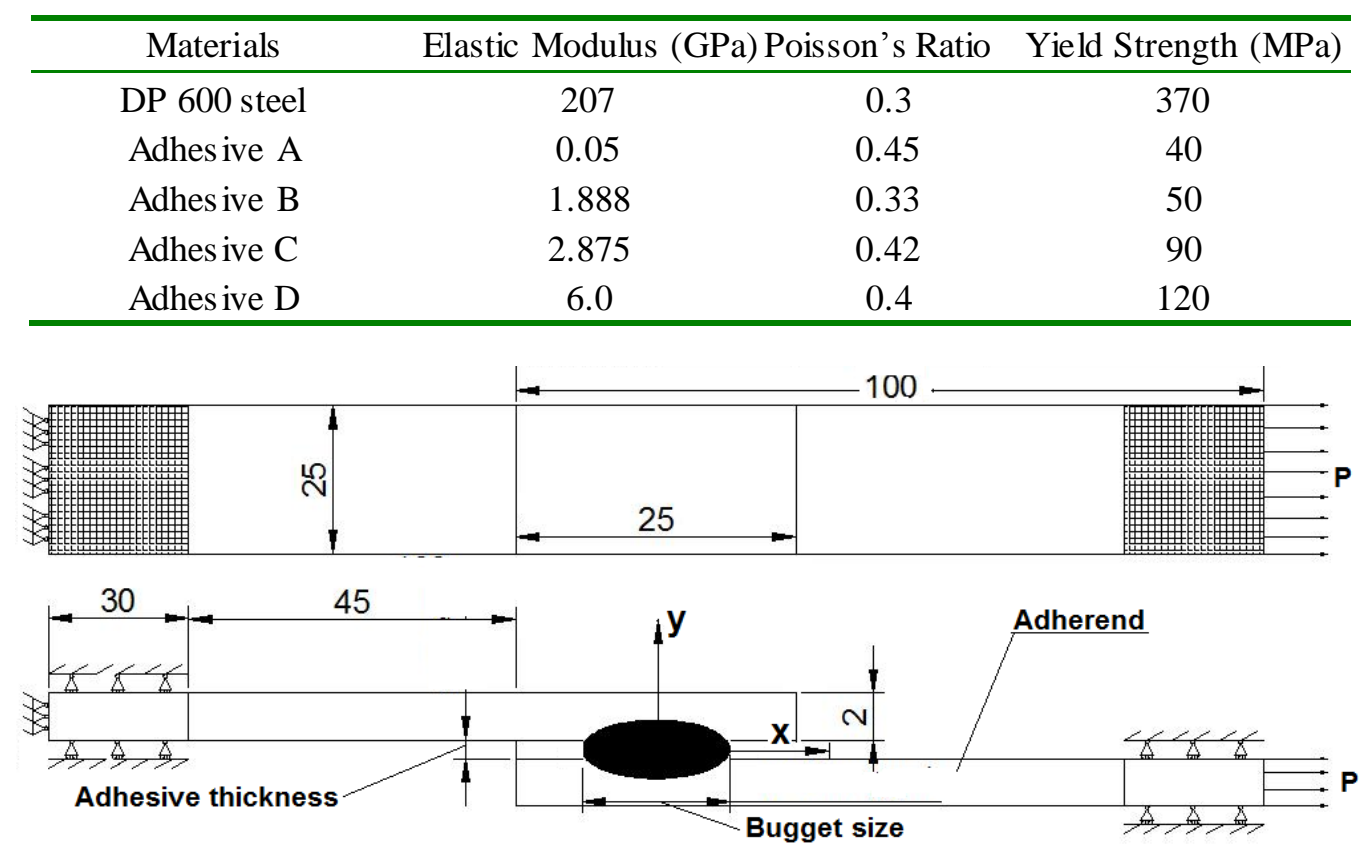

Fig.1 Finite element model (unit: $\mathrm{mm}$ )

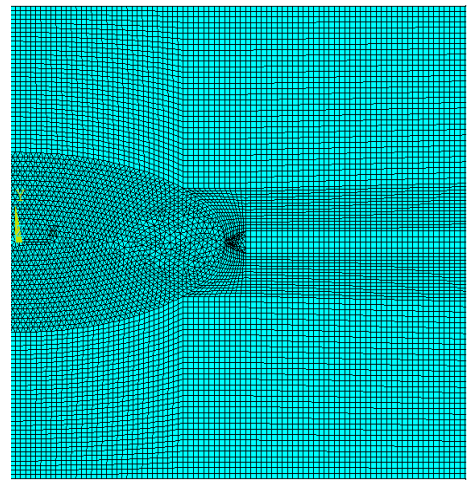

(a)

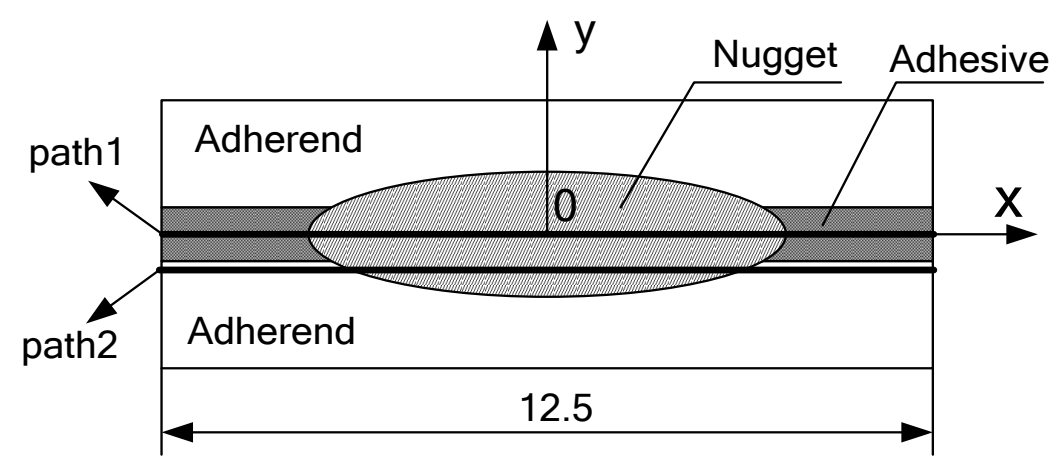

(b)

Fig.2 Finite-element meshes for right half of over lap zone (a) and the paths (b)

\section{Results and Discussion}

The effect of the elastic modulus of adhesives on the stress distribution along $\mathrm{x}$ axis (path1) is presented in Fig.3. The results show that the peak values of the stress components $S x, S y, S x y$ and the von Mises equivalent stress $S e q v$ are significantly affected by the elastic modulus of adhesives and the stress distribution along the $\mathrm{x}$-axis is symmetrical to the center of the overlap zone. For the peak value of the stress $S x, S y, S x y$ and $S e q v$ occurred at the points near both ends of the over lap zone in the joint, it is increased significant as the elastic modulus of adhesives increased. For instance, the peak value of stress longitudinal $S x$ is increased $495 \%$ from about $0.88 \mathrm{MPa}$ to about $5.24 \mathrm{MPa}$ when the elastic modulus of adhesives increased from $0.05 \mathrm{GPa}$ to $6 \mathrm{GPa}$ (Fig. 3a). It is clear that the increase of the von Mises stress Seqv at the point near the both ends along the path1 in the weld-bonded single lap DP 600 steel joint is evidently as the elastic modulus of adhesives increased (Fig. 3d). Compared the results obtained with what reported in Ref. [4], the effect of the elastic modulus of adhesives on the longitudinal stress $S x$ in this work is similar to it. But for the peak stress $S x$ occurred in the nugget when the elastic modulus of adhesives was $0.05 \mathrm{GPa}$, it is relative lower (18.5 MPa) than that from aluminum joint (50 MPa) [4]. There are three differences between them such as adherend (steel to aluminum), load ( $2 \mathrm{kN}$ to $3 \mathrm{kN}$ ) and the length of lap zone (25 $\mathrm{mm}$ to $12.5 \mathrm{~mm}$ ). The stress distribution tendency of the peel stress $S y$ (Fig. $3 b$ ) is not similar to that of $S x$, 
$S x y$ or $S e q v$ in the region of nugget. There is a couple of negative value $S y$ occurred at the edges of the nugget when the elastic modulus of adhesives is equal to $0.05 \mathrm{GPa}$ although there is a greater peak value occurred at same point for the stress $S x, S x y$ or $S e q v$.
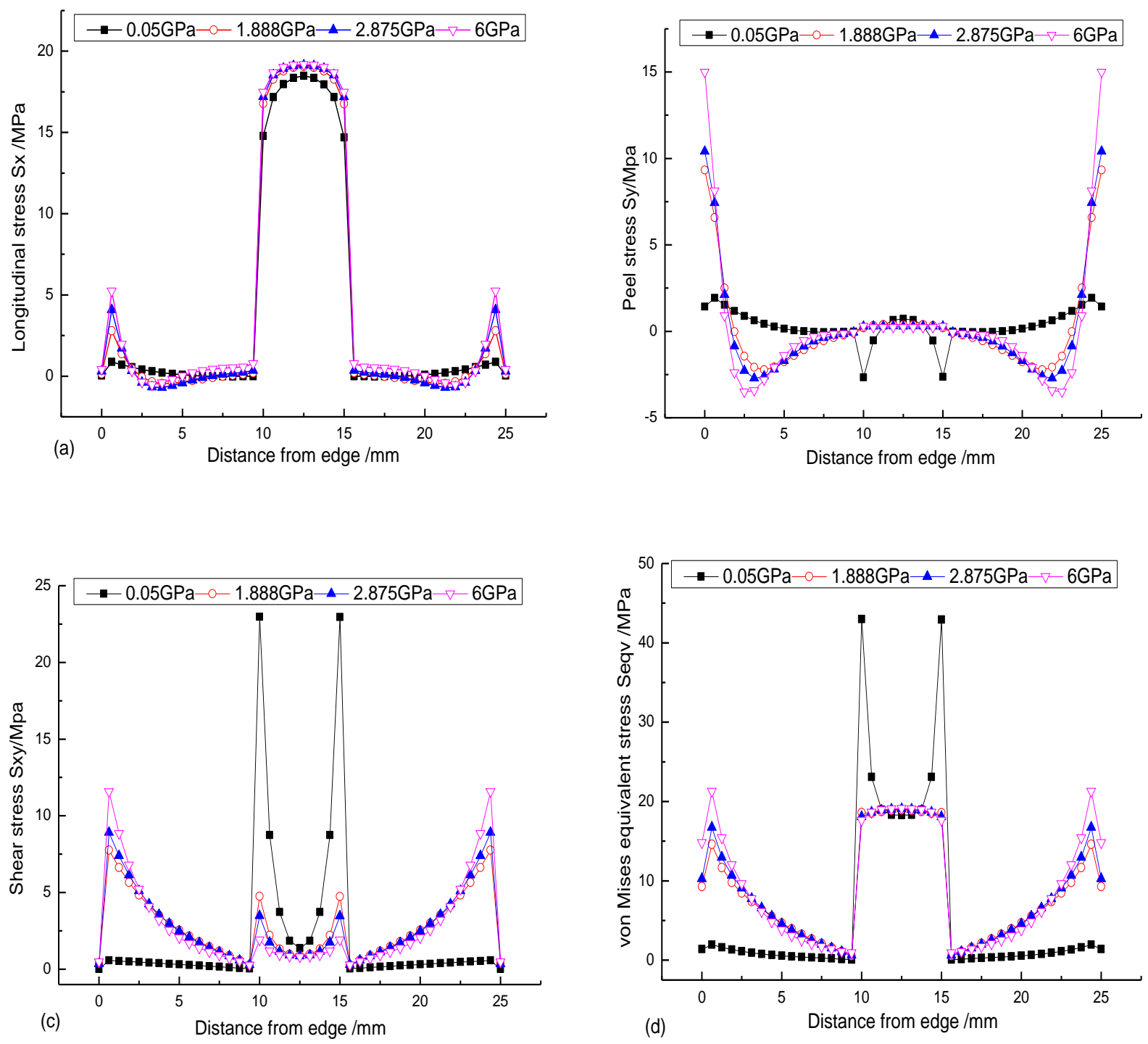

Fig.3 Effect of the elastic modulus of adhesives on the stress distribution along the mid-bond line: (a) longitudinal stress Sx; (b) peel stress Sy; (c) shear stress Sxy and (d) von Mises equivalent stress

Seqv

The effect of the elastic modulus of adhesives on the stress distributed in the adherend near the interface (path2, $\mathrm{y}=-0.15 \mathrm{~mm}$ ) is shown in Fig.4. The results show that the values of the stress $S x$, Sxy and Seqv are not varied distinguish as the elastic modulus of adhesives is greater than 0.05 GPa. For peel stress $S y$, the peak values at point of the left end of the overlap zone is decreased first as the elastic modulus of adhesives increased from $0.05 \mathrm{GPa}$ to $6 \mathrm{GPa}$ and then increased significant from about - $9 \mathrm{MPa}$ to about $8 \mathrm{MPa}$ as the distance increased from $0(\mathrm{x}=-12.5 \mathrm{~mm})$ to $0.625 \mathrm{~mm}$. The difference of the peak value among all the four elastic modulus of adhesives is not significant. And a valley value as well as a peak value occurred at the points corresponding to the left and right edge of the nugget and the absolute value is decreased as the elastic modulus of adhesives increased (Fig. 4b). So the peel stress $S y$ distributed in the adherend near the interface is more complex to the one distributed along the path1 (Fig. 3b). 

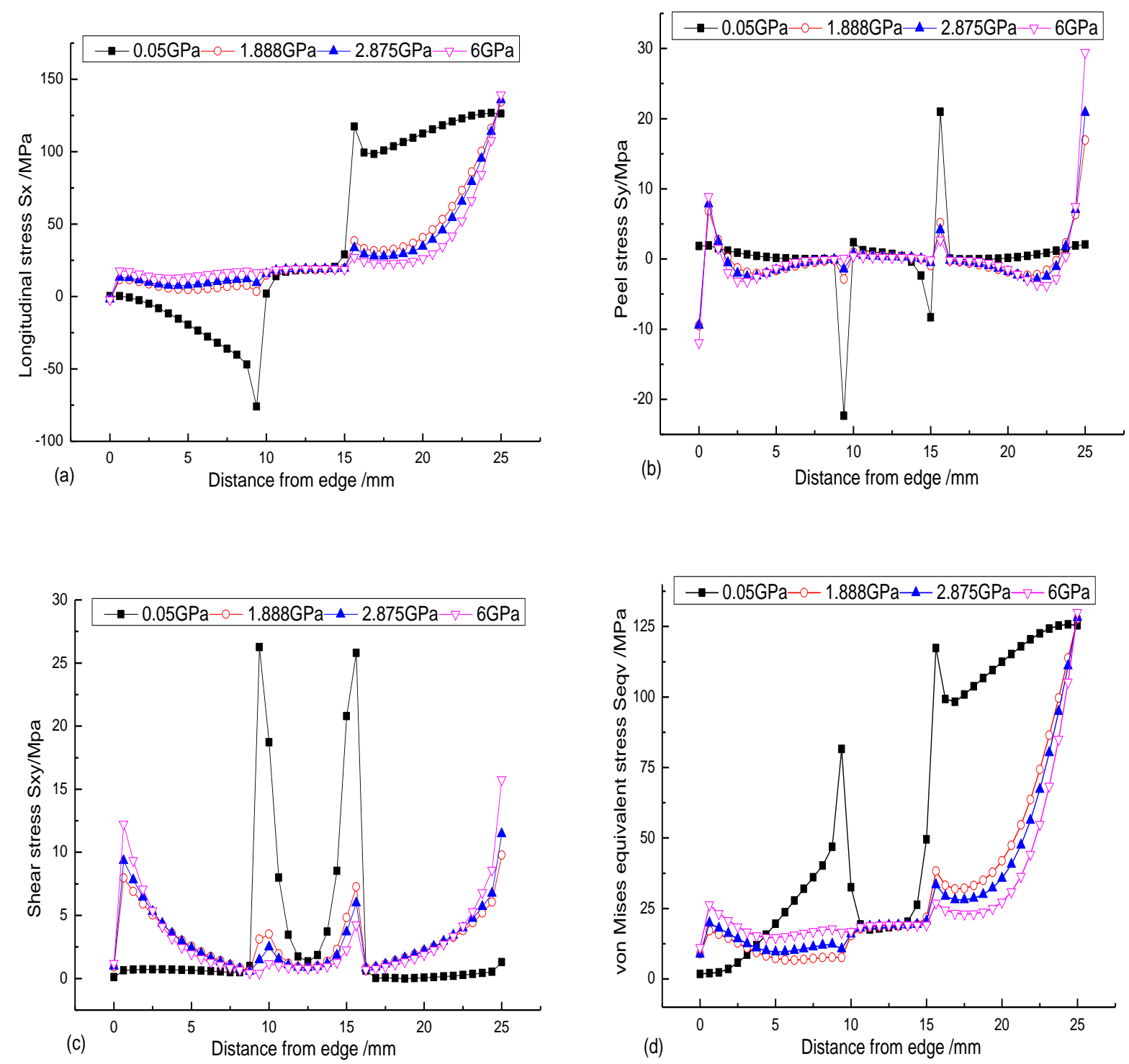

Fig.4 Effect of the elastic modulus of adhesives on the stress distribution in adherend near the interface: (a) longitudinal stress Sx; (b) peel stress Sy; (c) shear stress Sxy and (d) von Mises equivalent stress Seqv.

\section{Summary}

The results obtained from this work show that all the peak values of the stresses along the mid-bondline at the points near both ends of the over lap zone in the joint are increased significantly as the elastic modulus of adhesives increased. The stress distribution tendency of the peel stress $S y$ is not similar to that of $S x, S x y$ or $S e q v$ in the region of nugget. For the peak value of the stress $S x, S x y$ and Seqv along the adherend near the interface, it is not varied distinguish as the elastic modulus of the adhesives is greater than $1.888 \mathrm{GPa}$. It is recommended that the suitable elastic modulus of adhesives be about $2 \mathrm{GPa}$ for a weld-bonded single lap DP 600 steel joint.

\section{Acknowledge ments}

The authors would like to acknowledge the financial supported by the National Natural Science Foundation of China (50975160). 


\section{References}

[1] F. Hayat, Comparing properties of adhesive bonding, resistance spot welding, and adhesive weld bonding of coated and uncoated DP 600 steel, Int. J. Iron and Steel, 18(n9, 2011) 70-78

[2] B. Bartczak, J. Mucha, T. Trzepiecinski, Stress distribution in adhesively-bonded joints and the loading capacity of hybrid joints of car body steels for the automotive industry, Int. J. Adhesion \& Adhesives, 45 (2013) 42-52

[3] S.M. Darwish, A. Al-Samhan, Design rationale of weld-bonded joints, Int. J. Adhesion \& Adhesives, 24 (2004) 367-377

[4] M. You, J. -L. Yan, X. -L. Zheng, et al, Effect of elastic modulus of adhesives on stress distribution in weld-bonded joints, J. Aeronautical Mater., 29 (n3, 2009) 98-101 (In Chinese)

[5] M. You, J. -L. Yan, X. -L. Zheng, et al, Effect of adhesive for fillet on stress in weld-bonded joints, Key Engineering Materials, 450 (2011) 502-505

[6] M. You, J. -J Xu, J. -Li L, et al, Effect of Nugget Size on Stress Distribution in Weld-boded Single Lap DP 600 Steel Joint: accepted by Materials Science Forum (2016) 